\title{
Finite Element METHOD ON THE EXAMPLE Analysis of The Construction Pit Safety
}

\author{
COLAK, A. \& PRSKALO, M.
}

Abstract: The method used in this paper to protect a construction pit by a pile wall is based on checking the stability of the pile wall in the program GEO5 - FEM (Finite Element Method), which gives values of stresses and strains in soil. Since safety factors obtained by the program were small, indicating structural instability, it is necessary to additionally support the structure by struts. The adopted solutions obtained in Sheeting Check (GEO 5) are based on Eurocode 7, specifically using the design approach DA1, combination 1 and combination 2, adopting adequate partial coefficients.

Key words: pile wall, finite element method
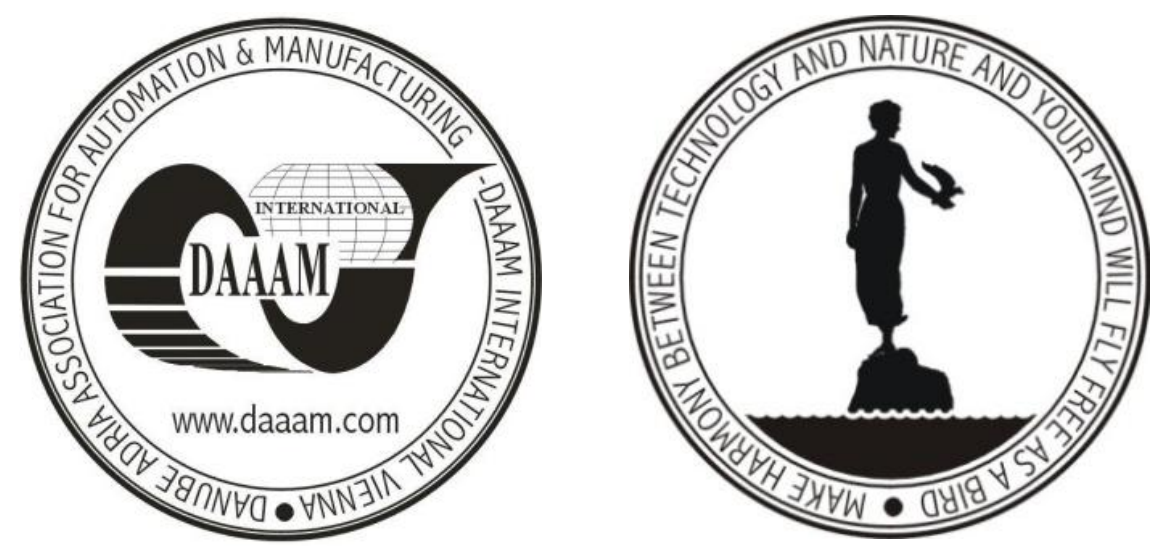

Authors' data: Colak, A[nela]*; PhD., Prskalo, M[aja]**; *Faculty of Economics University of Mostar, Matice hrvatske bb, 88 000, Mostar, Bosnia and Herzegovina, **Faculty of Civil Engineering University of Mostar, Matice hrvatske bb, 88000 , Mostar, Bosnia and Herzegovina, mprskalo39@yahoo.com, anela.colak@sve-mo.ba

This Publication has to be referred as: Colak, A[nela] \& Prskalo, M[aja] (2012). Finite Element Method on the Example Analysis of the Construction Pit Safety, Chapter 20 in DAAAM International Scientific Book 2012, pp. 233-240, B. Katalinic (Ed.), Published by DAAAM International, ISBN 978-3-901509-86-5, ISSN 17269687, Vienna, Austria

DOI: $10.2507 /$ daaam.scibook.2012.20 


\section{Introduction}

The common geotechnical practice is to use modern numerical methods, such as the finite element method, differential method, and boundary element method. These methods model the soil-structure interaction and analyze stress strain states in the foundation soil and structure in all construction stages. Unlike usual analytical methods, which directly calculate dimensions of support structures (such as anchors, struts etc.), numerical methods require support structures to be predefined (Logar, 2009).

\section{Previous research}

Various theoretical and numerical procedures are developed to obtain approximate solutions of real distribution of stresses in a structure-soil interface. A practically reasonable approximation of the actual state is achieved by developing numerical procedures and thoroughly investigating deformation properties of soil (Veric, 2000).

GEO5 is a set of programs designed for solving geotechnical problems and each of the programs is intended for solving a different geotechnical problem. The programs are based on the analytical calculation method and finite element method (FEM), Figure 1. By using the finite element method, the FEM program evaluates stresses and strains in soil around a structure and stability of the structure. Finite element method computations of the FEM program established that our sheet pile wall was unstable without support, i.e. without a strut. For that reason, further computations were carried out using the Sheeting Check program, with a strut placed 3.0 in depth and sized based on acting forces. Sheeting Check allows wall stability testing and provides moments and forces acting on the pile wall.

\section{Numerical methods}

With these calculations, we obtain ultimate states of bearing capacity in terms of characteristic values of parameters of soil and structure and characteristic geometry of elements of the structure, anchor and strut, which are considered as linear elastic elements with regard to actual characteristic stiffness. Sizing is performed based on values of forces obtained according to EC7, with application of partial factors.

The geotechnical Eurocode (Eurocode 7, 1997) consists of two parts:

- EN 1997-1 Geotechnical design - Part 1: General rules

- EN 1997-2 Geotechnical design - Part 2: Ground investigation and testing.

The entire structure and stiffness of structural elements must be predefined for calculation according to the finite element method. Diaphragm should be calculated as elastic linear elements with constant stiffness. For the C25/30 quality concrete, 30 $\mathrm{GPa}$ is adopted as the value of modulus of elasticity. The volume weight of concrete is $\gamma=25 \mathrm{kN} / \mathrm{m} 3$. Structural calculation is generally carried out in the following steps: 
- selection of characteristic values of material parameters,

- selection of the depth to which piles are driven,

- stress-strain analysis of the structure using the finite element method and sizing of elements of the protective structure,

- calculation of active pressures and equivalent forces acting on the pile wall.

\section{Fundamentals of the finite element method}

The finite element method is part of discrete analysis methods. Unlike other numerical methods, based on mathematical discretization of boundary problem equations, the finite element method is based on physical discretization of the observed area. Instead of an element of differentially small dimensions, the basis for all studies is part of an area of finite dimensions, smaller area or finite element. Therefore, the basic equations used to describe the state in individual elements, and to formulate the problem as a whole, are ordinary algebraic equations (algebraic polynomials) instead of differential or integral ones.

In terms of physical interpretation, this means that the area under consideration, as a continuum with infinitely many degrees of freedom, is replaced by a discrete model of interconnected finite elements, with a finite number of degrees of freedom. Considering that the number of discrete models for a boundary problem is infinitely large, the main task is to choose the model that best approximates the relevant boundary problem. The essence of approximating continuum according to the finite element method consists in the following:

- Using imagined lines or areas, the considered area of continuum is divided into a certain number of smaller areas of finite dimensions. Individual smaller areas are called finite elements, and the set of them for the entire area is called the system or grid of finite elements.

- The assumption is that finite elements are interconnected in a finite number of points that are adopted on contour of elements. These points are called nodal points or nodes.

- The state in every finite element (e.g. displacement field, strain, stresses, etc.) is described using interpolation functions and a finite number of parameters in nodes which represent primary unknowns in the finite element method.

- All principles and procedures applicable to classical discrete systems apply to analysis and calculation of a finite element system.

\section{Examples of numerical modeling}

Calculations of stability and strains of a pile wall solution $40 \mathrm{~cm}$ in thickness were carried out by geostatic analyses. After that, sizing of piles and strut elements was performed. We selected the piles $400 \mathrm{~mm}$ in diameter and 11 and $12 \mathrm{~m}$ in length, with the axis-to-axis distance of $70 \mathrm{~cm}$. Considering the presence of groundwater 
above the design excavation bottom, a low-permeability barrier was used as the design solution to protect the construction pit. Grouting decreased permeability of the medium and made the whole barrier low-permeable. Temporary struts were also placed as an extra protection measure because the pile wall alone did not provide sufficient safety.

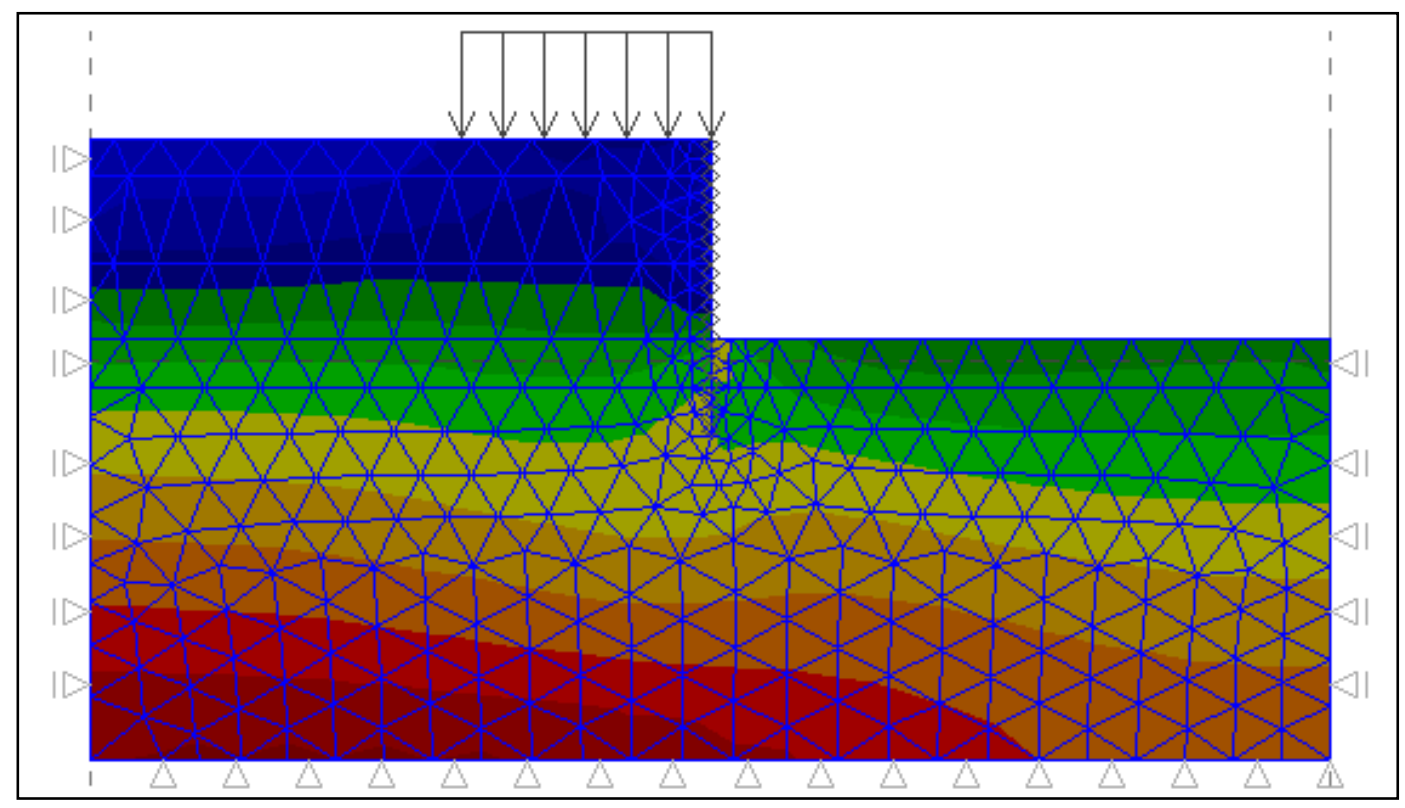

Fig. 1. Results obtained using the FEM method

Struts were placed horizontally to support strut beams along the pile wall. Metal HEB profiles, sized according to acting forces, were used as struts and strut beams. One of the solutions obtained using the finite element method in the FEM program is shown in Figure 2.

\begin{tabular}{|c|c|c|c|}
\hline $\begin{array}{c}\text { Design approach } \\
\text { DA1 }\end{array}$ & Effects & $\begin{array}{c}\text { Soil } \\
\text { parameters }\end{array}$ & $\begin{array}{c}\text { Soil resistance } \\
\mathrm{R} 1\end{array}$ \\
\hline Combination 1 & $\gamma_{\mathrm{G}}=1.35$ & $\gamma_{\varphi}=\gamma_{\mathrm{c}}=1.0$ & $\gamma_{\mathrm{R} ; \mathrm{e}}=\gamma_{\mathrm{R} ; \mathrm{v}}=1.0$ \\
& $\gamma_{\mathrm{Q}}=1.5$ & $\gamma_{\mathrm{cu}}=1.0$ & $\gamma_{\mathrm{R} ; \mathrm{h}}=1.0$ \\
\hline Combination 2 & $\gamma_{\mathrm{G}}=1.35$ & $\gamma_{\varphi}=\gamma_{\mathrm{c}}=1.0$ & $\gamma_{\mathrm{R} ; \mathrm{e}}=\gamma_{\mathrm{R} ; \mathrm{v}}=1.0$ \\
& $\gamma_{\mathrm{Q}}=1.5$ & $\gamma_{\mathrm{cu}}=1.0$ & $\gamma_{\mathrm{R} ; \mathrm{h}}=1.0$ \\
\hline
\end{tabular}

Tab. 1. Values of partial safety factors for support structures - design approach PP1 (Prskalo, 2011)

It is always necessary to choose a suitable model of soil with adequately described changes that occur when excavating a construction pit. To model such problems, it is generally appropriate to use a non-linear model of soil with consolidation (e.g. the Hardening Soil Model) because of non-uniform pressures. For simplicity of the example, an ideal elasto-plastic Mohr-Coulomb model of soil, with characteristics equal to those applied in the analytical calculation, is selected here. Some computer programs for design based on the finite element method also allow 
numerical calculations of groundwater flows in stationary and non-stationary conditions. Effects of moments and transverse forces on the pile wall were calculated according to the design approach 1, combinations 1 and 2, with values of partial safety factors shown in Table 1.

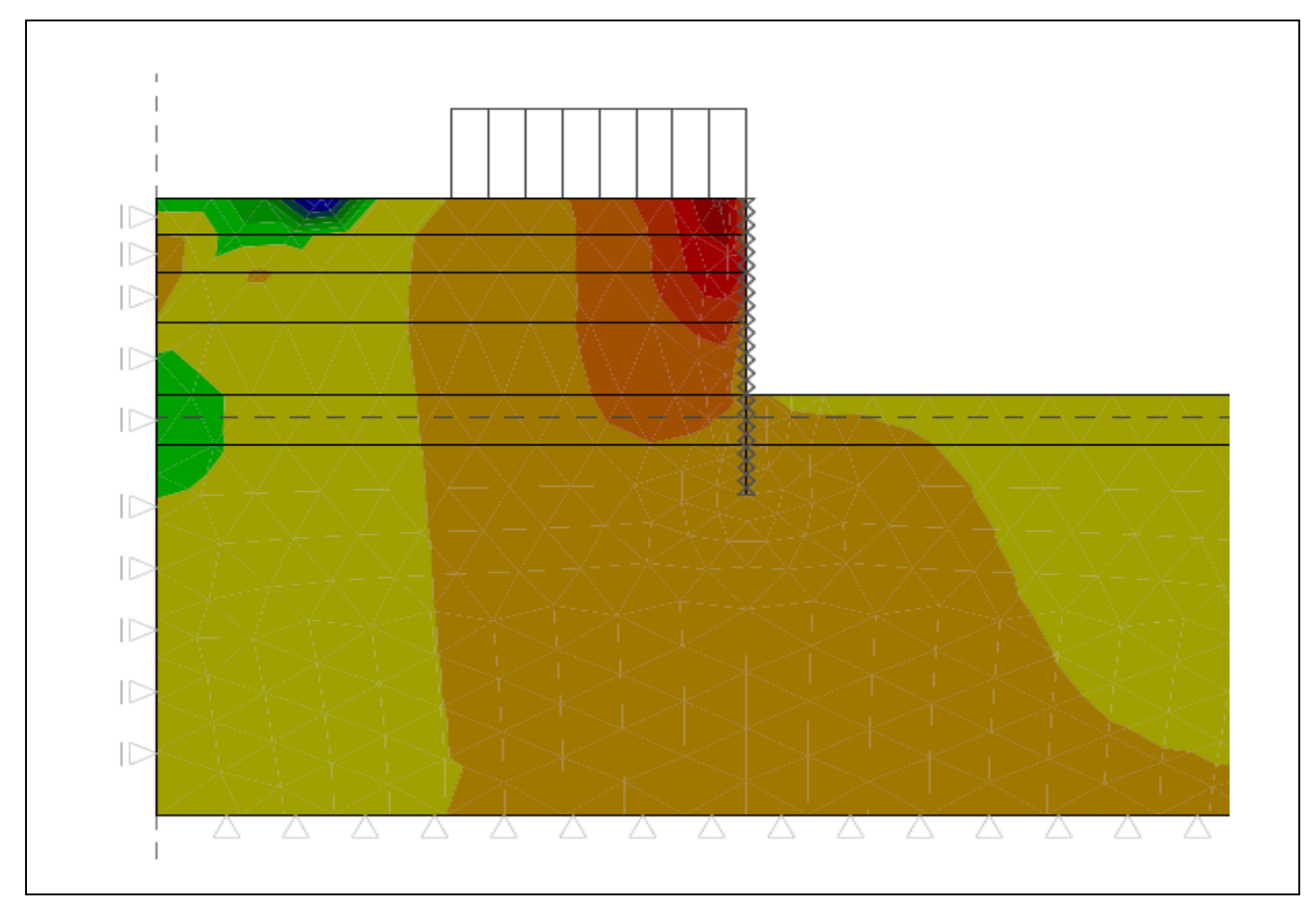

Fig. 2. Results obtained by the FEM method, settlement of soil

The value of active pressure acting on the pile structure is taken as a continuous load on the strut beam. This solution is conservative because it assumes that the strut beam takes the full equivalent force of active pressure, fully disregarding rigidity of the pile wall, but it is on the safe side and justified in view of possible consequences of oversizing. Values of active pressure forces are applied as a continuous load and we obtained the maximum values of moment and transverse forces, horizontal displacement and pressures on the diaphragm under effects of the active pressure, Table 2, Figures 3, 4 .

\begin{tabular}{|l|r|l|c|}
\hline \multicolumn{1}{|c|}{$\begin{array}{c}\text { Design approach } \\
\text { DA1 }\end{array}$} & $\begin{array}{c}\mathrm{M}_{\max } \\
(\mathrm{kNm} / \mathrm{m})\end{array}$ & $\begin{array}{l}\mathrm{Q}_{\max } \\
(\mathrm{kN} / \mathrm{m})\end{array}$ & $\begin{array}{c}\text { Horizontal displacement } \\
\text { of the diaphragm } \\
\mathrm{U}_{\max }(\mathrm{mm})\end{array}$ \\
\hline Combination 1 & 202.64 & 167.94 & 10.5 \\
\hline Combination 2 & 150.69 & 127.50 & 9.1 \\
\hline
\end{tabular}

Tab. 2. Results of calculation according to the finite element method 


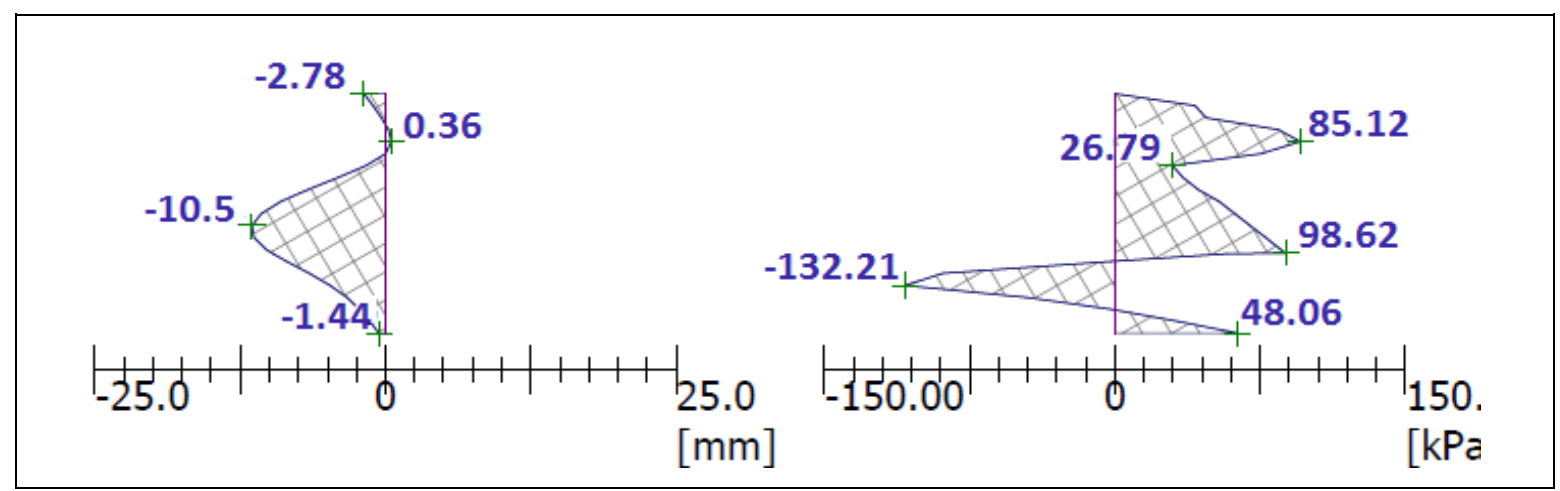

Fig. 3. Displacement of structure and pressure acting on structure PP1, combination 1

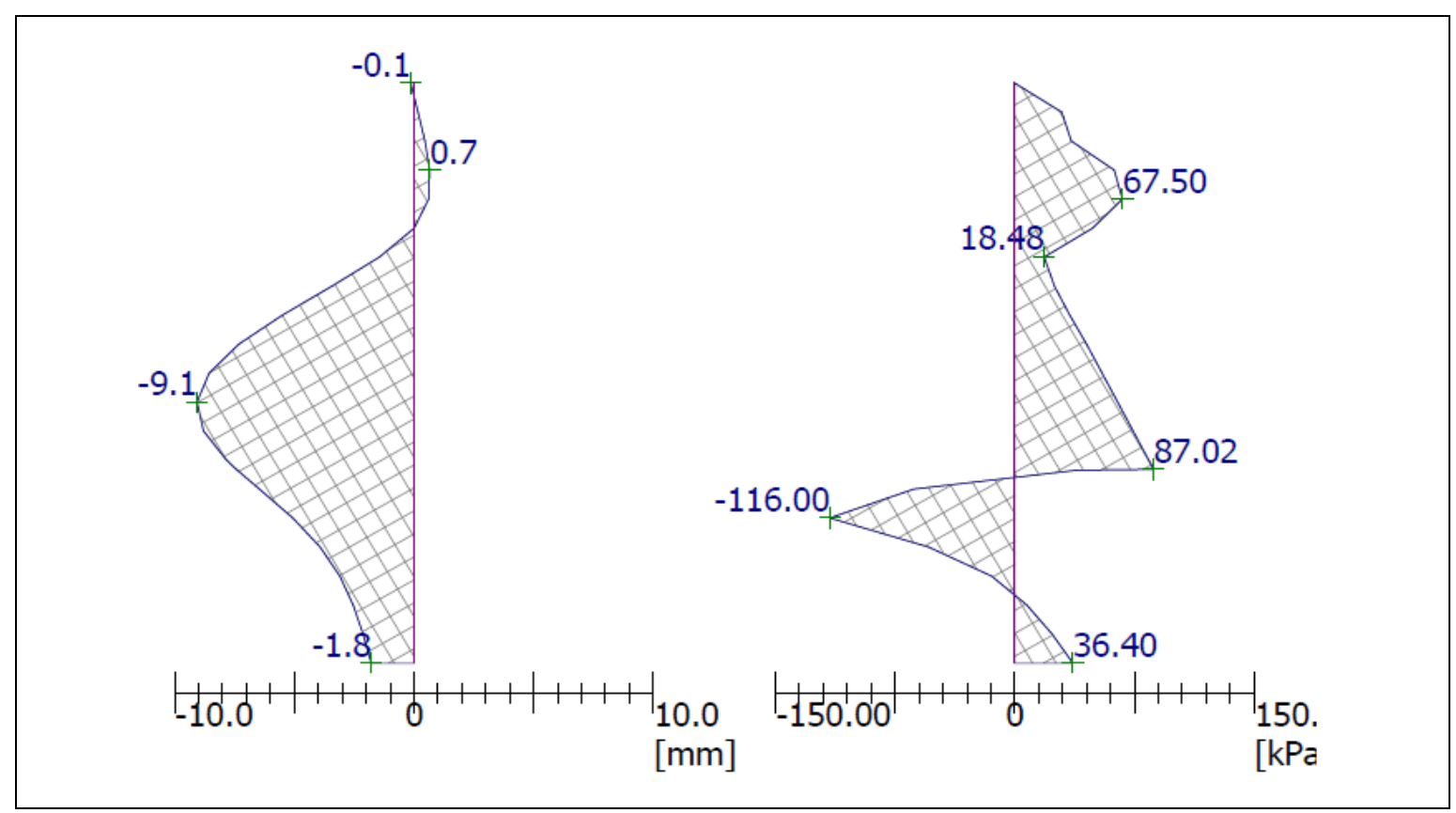

Fig. 4. Displacement of structure and pressure acting on structure PP1, combination 2

Calculation forces, based on which struts and strut beams are sized, is $N_{s d}=1204 \mathrm{kN}$. $\mathrm{A}_{\mathrm{pot}}=\mathrm{A} \cdot \mathrm{f} \frac{\gamma}{\gamma_{\text {мо }}}=54,3 \cdot \frac{23,5}{1,1}=1660 \mathrm{kN}>1204 \mathrm{kN}, \Rightarrow \mathrm{HE} 180 \mathrm{~B}$ from European wide flange beams: Dimension and Properties.

Classification of the cross section:

- Crest: $\frac{\mathrm{d}}{\mathrm{t}_{\mathrm{w}}}=\frac{122}{8,5}=14,35<33 \varepsilon=33$

- Flange: $\frac{\mathrm{c}}{\mathrm{f}}=\frac{90}{14}=6,428 \leq 10 \varepsilon=10$

- Element resistance:

- $\lambda_{1}=\pi \sqrt{\frac{E}{f_{y}}}=93,91$

- From the moment diagram $\beta=1,0$

- $1_{\mathrm{iy}}=1_{\mathrm{iz}}=1 \cdot \beta=7,75 \cdot 1,0=7,75 \mathrm{~m}$ 
- $\lambda_{\mathrm{y}}=\mathrm{l}_{\mathrm{iy}} / \mathrm{i}_{\mathrm{y}}=775 / 7.66=101.17$

- $\underline{\lambda}_{\mathrm{y}}=\lambda_{\mathrm{y}} / \lambda_{1}=114.3 / 93.91=1.07 \Rightarrow \chi=0,543$

- $\lambda_{\mathrm{z}}=\mathrm{1}_{\mathrm{iz}} / \mathrm{i}_{\mathrm{z}}=775 / 4.57=169.58$

- $\underline{\lambda}_{\mathrm{z}}=\lambda_{\mathrm{z}} / \lambda_{1}=191.35 / 93.91=1.805 \Rightarrow \chi=0,227$

The minimum value of $\chi$ is adopted.

$\mathrm{N}_{\mathrm{b}, \mathrm{Rd}}=0,227 \cdot 1660 \cdot 4,625=1742 \mathrm{kN}>1204 \mathrm{kN}$

Resistance to lateral buckling:

- $\mathrm{g}=0 ; \mathrm{G}=8077 \mathrm{kN} / \mathrm{cm}^{2} ; \mathrm{c}_{1}=1.132 ; \mathrm{c}_{2}=0.459 ; \mathrm{k}=1.0 ; \mathrm{k}_{\mathrm{w}}=1.0$

- $\mathrm{M}_{\mathrm{c}, \mathrm{R}}=\mathrm{c}_{1} \frac{\pi^{2} \cdot \mathrm{E} \cdot \mathrm{I}_{\mathrm{z}}}{(\mathrm{k} \cdot \mathrm{l})^{2}}\left[\mathrm{c}_{2} \cdot \mathrm{g} \sqrt{\frac{\mathrm{k}^{2} \cdot \mathrm{I}_{\mathrm{w}}}{\mathrm{k}_{\mathrm{w}}^{2} \cdot \mathrm{I}_{\mathrm{z}}}}+\sqrt{\frac{(\mathrm{k} \cdot \mathrm{l})^{2} \cdot \mathrm{G} \cdot \mathrm{I}_{\mathrm{z}}}{\pi^{2} \cdot \mathrm{E} \cdot \mathrm{I}_{\mathrm{z}}}}+\left(\mathrm{c}_{2} \cdot \mathrm{g}\right)^{2}\right]$

- $\mathrm{M}_{\mathrm{c}, \mathrm{R}}=24609 \mathrm{kNcm}=246,09 \mathrm{kNm}$

- $\Delta_{\mathrm{LT}}=\sqrt{\frac{\beta_{\mathrm{w}} \cdot \mathrm{w}_{\mathrm{pl}, \mathrm{y}} \cdot \mathrm{f}_{\mathrm{y}}}{\mathrm{M}_{\mathrm{cR}}}}=0,69>0,4 ; \chi_{\mathrm{LT}}=0,853$

- $\beta_{\mathrm{w}}=\frac{\mathrm{W}_{\mathrm{ef}, \mathrm{fy}}}{\mathrm{W}_{\mathrm{pl}, \mathrm{y}}}=1,0$

- $\mathrm{M}_{\mathrm{b}, \mathrm{Rd}}=\chi_{\mathrm{LT}} \frac{\beta_{\mathrm{w}} \cdot \mathrm{W}_{\mathrm{pl}, \mathrm{y}} \cdot \mathrm{f}_{\mathrm{y}}}{\gamma_{\mathrm{M}}}=0,853 \cdot 481,4 \cdot \frac{35,5}{1,1}=132,52>110,30 \mathrm{kNm}$

The wall of the construction pit consists of piles $40 \mathrm{~cm}$ in diameter, spaced $70 \mathrm{~cm}$ apart. The following were obtained by calculation: $\operatorname{maxM}=150.70 \mathrm{kNm}$ and $\max \mathrm{Q}=132.72 \mathrm{kN}$. Adopted values of parameters for pile sizing are:

\begin{tabular}{|l|l|l|}
\hline Concrete & Longitudinal & Stirrups \\
C $25 / 30$ & reinforcement & $\Phi 10$ \\
$\mathrm{f}_{\mathrm{ck}}=25 \mathrm{~N} / \mathrm{mm}^{2}$ & B 500 & B 500 \\
$\tau_{\mathrm{rd}}=0.3 \mathrm{~N} / \mathrm{mm}^{2}$ & $\mathrm{f}_{\mathrm{yk}}=500 \mathrm{~N} / \mathrm{mm}^{2}$ & $\mathrm{f}_{\mathrm{yk}}=500 \mathrm{~N} / \mathrm{mm}^{2}$ \\
$\gamma_{\mathrm{c}}=1.3$ & $\gamma_{\mathrm{c}}=1.15$ & \\
& & \\
\hline
\end{tabular}




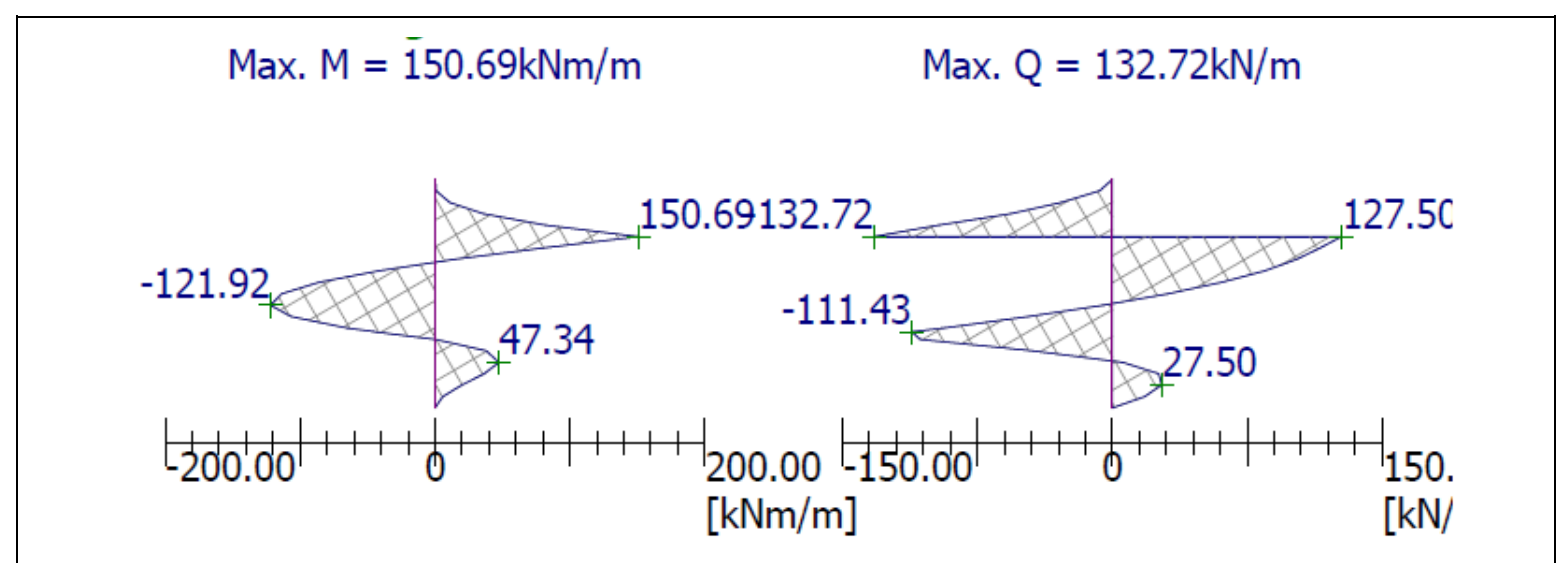

Fig. 5. Values of moments and transverse forces (GEO 5, 2010)

\section{Conclusion}

To ensure safe work during construction of the foundation and basement, the construction pit situated close to urban environment (two structures, roads and underground installations) was protected according to design elements and investigation results. Sizing of the pile wall was carried out on the basis of the forces computed using the software suite. Results of calculations based on the finite element method gave the values of maximum moment, maximum transverse force, and maximum horizontal displacement of the diaphragm according to Eurocode 7, design approach 1, combinations 1 and 2, with previously defined parameters of the support structure, and they serve as a basis for further pile wall stability calculations. Also, profiles and materials for struts and strut beams should be varied in order to be sized in a most cost-efficient manner according to acting forces.

\section{References}

Eurocode 7, (1997). Part 1 (BS EN 1997-1) Geotechnical design-General rules and Part 2 (prEN 1997-2) Ground investigation and testing

Logar, J. \& Pulko, B. (2009). Priročnik za projektiranje gradbenih konstrukcij po evrokod standardih (Guide for design of engineering structures according to Eurocode standards), Eurocode 7: Geotechnical design, University of Ljubljani, Faculty of Civil Engineering, ISBN: 978-961-6724-03-6, Ljubljana

Jurak, M. (2004) Metoda konačnih elemenata (The Finite Element Method) lectures: Faculty of Science, University of Zagreb

Prskalo, M. (2011). Zbirka riješenih zadataka iz Mehanike tla s primjenom EC 7 (Book of solved problems in soil mechanics with application of EC7), Faculty of Civil Engineering, University of Mostar

Verić, F. (2000). Savitljive temeljne konstrukcije (Flexible foundation structures), Authorized lectures, Faculty of Civil Engineering, University of Zagreb, nstitute for Geotechnics

*** GEO 5 (2010) FEM, SHEETING CHECK, Software, version 5.10.32.0, www.finesoftware.eu 